\title{
A Finite Element Analysis Study Comparing 3 Internal Fixation Techniques in Mandibular Sagittal Split Osteotomy
}

\author{
Muhammad Kamil Hassan ${ }^{1,2 *}$, Michael Ring ${ }^{3}$, Leo F. A. Stassen ${ }^{4}$ \\ ${ }^{1}$ Dublin Dental School and Hospital, Trinity College Dublin, Dublin, Ireland \\ ${ }^{2}$ St. James's Hospital Dublin, Dublin, Ireland \\ ${ }^{3}$ Dublin Institute of Technology, Dublin, Ireland \\ ${ }^{4}$ Dublin Dental School and Hospital, Trinity College Dublin, Dublin, Ireland \\ Email: ^kamil.hassank@gmail.com
}

How to cite this paper: Hassan, M.K., Ring, M. and Stassen, L.F.A. (2018) A Finite Element Analysis Study Comparing 3 Internal Fixation Techniques in Mandibular Sagittal Split Osteotomy. International Journal of Otolaryngology and Head \& Neck Surgery, 7, 298-311.

https://doi.org/10.4236/ijohns.2018.75030

Received: August 6, 2018

Accepted: September 3, 2018

Published: September 6, 2018

Copyright $\odot 2018$ by authors and Scientific Research Publishing Inc. This work is licensed under the Creative Commons Attribution International License (CC BY 4.0).

http://creativecommons.org/licenses/by/4.0/

\begin{abstract}
Purpose: To analyse, and compare using finite element analysis, the biomechanical properties of the $1.7 \mathrm{~mm}$ miniplate fixation against 2 conventional fixation techniques ( $2.0 \mathrm{~mm}$ bi-cortical screws and $2.0 \mathrm{~mm}$ miniplate) used in the mandibular sagittal split osteotomy. Methods: A 3-D virtual mandible model was constructed using images from CT scan. Sagittal split osteotomy was carried out virtually, and the fixation techniques were applied onto the model. 9 virtual models consisted of the 3 fixation techniques with mandibular movements of $3 \mathrm{~mm}$ setback, $3 \mathrm{~mm}$ advancement and $7 \mathrm{~mm}$ advancement were developed. Bite forces of 50, 75 and $100 \mathrm{~N}$ were applied for incisor bite simulation and 100, 200 and $300 \mathrm{~N}$ for molar biting force. Finite element analysis was carried out in Solidworks, and readings of stresses and displacement were recorded. Wilcoxon rank sum test was applied and P-value of 0.05 was set for statistical analysis. Results: In this manuscript the authors have compared 3 internal fixation techniques in mandibular sagittal split osteotomy. There was a statistically significant difference for both stress and displacement readings between the $1.7 \mathrm{~mm}$ miniplate, the $2.0 \mathrm{~mm}$ bi-cortical screws and the $2.0 \mathrm{~mm}$ miniplate for all mandibular movements. For the 1.7 $\mathrm{mm}$ miniplate vs $2.0 \mathrm{~mm}$ bi-cortical screws, the stress reading was $(\mathrm{P}=$ $3.063 \mathrm{e}-08, \mathrm{~W}=314)$, and for displacement was $(\mathrm{P}=5.811 \mathrm{e}-05, \mathrm{~W}=282)$. For the $1.7 \mathrm{~mm}$ miniplate vs $2.0 \mathrm{~mm}$ miniplate, the stress reading was $(\mathrm{P}=$ $9.862 \mathrm{e}-4, \mathrm{~W}=263)$ and for displacement was $(2.05 \mathrm{e}-2, \mathrm{~W}=235)$. Conclusion: The $1.7 \mathrm{~mm}$ miniplate has adequate strength to be used in mandibular sagittal split osteotomy, although statistically less rigid when compared to the conventional $2.0 \mathrm{~mm}$ miniplate and $2.0 \mathrm{~mm}$ bi-cortical screws, especially in larger movements.
\end{abstract}




\section{Keywords}

Orthognathic, BSSO, Rigid Fixation, Biomechanical, Finite Element Analysis

\section{Introduction}

Providing adequate stability after orthognathic surgery is important to minimize complications and relapse. The fixation techniques used in mandibular orthognathic surgery are usually internal fixation, and over the years have switched from non-rigid wires, to more rigid screws, and titanium miniplates [1] [2]. The aim of providing stable fixation for the bone segments is to facilitate good bone healing, early mobilization of the jaws, and to prevent relapse [3].

Internal fixation techniques can be classified as rigid, semi-rigid/functionally stable or non-rigid. Historically, Bernd Spiessl in 1974 published the use of bi-cortical screws as rigid internal fixation that can prevent relapse in mandibular osteotomies, while Hans Luhr in 1979 introduced the principle of mini-plates in orthognathic surgery [2]. The $2.0 \mathrm{~mm}$ or larger miniplate system is commonly used for mandibular orthognathic surgery and trauma [4]. However, the use of smaller miniplate fixation in mandibular osteotomies is uncommon, but has been reported in the literature [5].

Biomechanical studies investigating the properties of various fixation techniques in mandibular osteotomies include in-vitro and finite element analysis studies [6] [7] [8] [9]. The finite element analysis is a mathematical method for solving problems of engineering, and mathematical physics. There is a growing interest in the use of finite element analysis (FEA) in the studies of human oral and maxillofacial biomechanics including maxillofacial trauma, zygomatic implants, dental implantology, and orthognathic surgery [10] [11]. The finite element method allows the analysis of biomechanical properties of bone and fixation techniques in various situations and loads.

This study used FEA to investigate the biomechanical properties of three internal fixation techniques $(1.7 \mathrm{~mm}$ miniplate with mono-cortical screws, $2.0 \mathrm{~mm}$ bi-cortical screws, and $2.0 \mathrm{~mm}$ miniplate with mono-cortical screws) used in mandibular orthognathic surgery, subjected to different biting forces and movements. It is also the first study to compare different mandibular osteotomy lengths on stresses in fixation techniques and displacements. The purpose of this study is to assess the biomechanical performance of the smaller $1.7 \mathrm{~mm}$ miniplate when compared to the other techniques.

\section{Materials and Methods}

The study uses finite element analysis (FEA), which is a computational study. This study was approved by the Dental Ethics Committee, Dublin Dental School and Hospital, Trinity College Dublin, Ireland. 


\subsection{Model Construction}

A pre-operative facial bones CT Scan of a 30-year-old, consenting female, who was undergoing surgery of the maxilla was used construct the mandible virtual model. The images of the scan were in $0.625 \mathrm{~mm}$ thickness and were converted into Digital Imaging and Communications in Medicine (DICOM) format. InVesalius software was used to extract the CT images, selecting the mandible bone only using the Hounsfield threshold, and converted into a 3D standard tessellation language file (STL) format [12]. The STL model was edited in Netfabb software, and any defects present were repaired. Only half of the mandible was preserved to reduce model complexity, ensure adequate computer resources, and create virtual models with less elements [13]. Rhinoceros software was used to fit a series of non-uniform rational B-splines (NURBS) around the hemi-mandible STL surface [14]. This created a surface model, which was opened as a solid mandible model, and used for FEA. The mandible's cancellous bone layer was developed separately using the same process.

In Solidworks, both the cortical mandible model and cancellous bone were combined to develop a cortical-cancellous mandible model [15]. This bi-layer mandible solid model underwent a virtual sagittal split osteotomy (Obwegeser technique with DalPont, Hunsuck and Epker modifications), which resulted in 2 segments; proximal and distal segment of the mandible (Figure 1).

The fixation techniques were developed in Solidworks. Screws in each technique were developed as smooth cylinders, and threads omitted. The $1.7 \mathrm{~mm}$ and $2.0 \mathrm{~mm}$ miniplate consisted of 4 mono-cortical screws of $5 \mathrm{~mm}$ length, while the $2.0 \mathrm{~mm}$ bicortical screws were developed with $15 \mathrm{~mm}$ and $11 \mathrm{~mm}$ length initially, and adjusted accordingly during model assembly. The $2.0 \mathrm{~mm}$ bicortical screws were applied in an inverted-L design, with 2 screws on the superior border and 1 screw inferiorly.
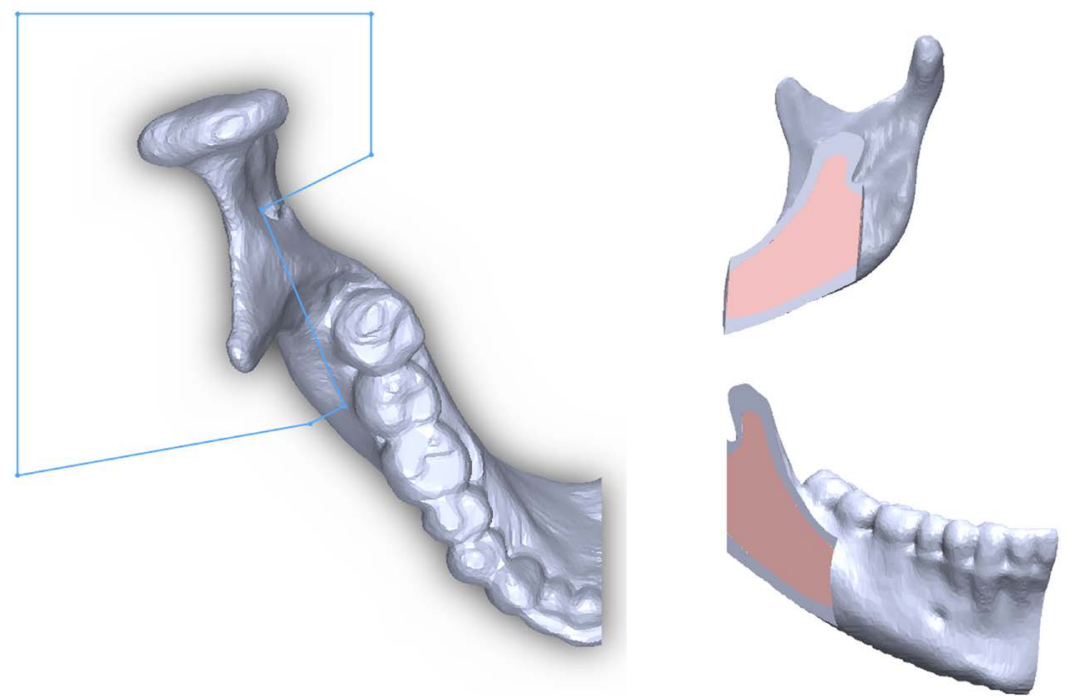

Figure 1. Sagittal split osteotomy carried out virtually resulting in proximal segment (upper right) and distal segment (lower right). 
A total of 9 assembly virtual models were developed, which incorporated the solid bi-layer mandible, the internal fixation techniques, and incorporating the various mandibular osteotomy movements as shown in Table 1.

\subsection{Material Properties}

Cortical and cancellous bone types were homogenous in all regions of the mandible. The bone properties were derived from previous literary data, and an average value was chosen to represent a normal healthy adult bone [16] [17] [18]. The fixation techniques had the properties of commercially pure titanium Ti-4AI-6V.

Table 2 shows the properties of each material used in the FEA. The elastic modulus is the ratio of the stress and strain of an object undergoing elastic deformation. Poisson's ratio is the ratio of the transverse strain and the longitudinal strain in an elastic body under longitudinal stress.

Mesh creation (discretization) and simulation analyses

Mesh creation or discretization is the process of breaking down the whole assembled mandible model into smaller finite elements. Following a mesh convergence test with limit of 5\% difference between successive mesh, each model consisted of maximum element size of $3 \mathrm{~mm}$, minimum element size of $0.5 \mathrm{~mm}$.

Table 1. Models with respective fixation technique and mandibular movements.

\begin{tabular}{ccc}
$\begin{array}{c}\text { Mandibular } \\
\text { movement }\end{array}$ & $\begin{array}{c}1.7 \mathrm{~mm} \\
\text { miniplate }\end{array}$ & $\begin{array}{c}2.0 \mathrm{~mm} \\
\text { miniplate }\end{array}$ \\
\hline $\begin{array}{c}3 \mathrm{~mm} \\
\text { setback }\end{array}$ & Mortical screws \\
\hline mm \\
advancement
\end{tabular}


Table 2. Material properties used in FEA.

\begin{tabular}{ccc}
\hline Material & Property & Value \\
\hline \multirow{2}{*}{ Titanium } & Elastic Modulus & $104.8 \mathrm{GPa}$ \\
& Poisson's ratio & 0.31 \\
& Density & $4428.8 \mathrm{~kg} / \mathrm{m}^{3}$ \\
Cortical Bone & Elastic Modulus & $17 \mathrm{GPa}$ \\
& Poisson's ratio & 0.3 \\
& Density & $2000 \mathrm{~kg} / \mathrm{m}^{3}$ \\
Cancellous Bone & Elastic Modulus & $300 \mathrm{MPa}$ \\
& Poisson's ratio & 0.3 \\
\hline
\end{tabular}

$1 \mathrm{GPa}=1000 \mathrm{MPa}\left(\mathrm{Pa}\right.$ is the Pascal unit which is the equivalence to Newton $/ \mathrm{m}^{2}$ ).

The number of elements in Model 4 was 136,450 elements, and this differs slightly in other models due to the type and size of fixation techniques, and mandibular movement.

The contact surfaces of the proximal and distal mandible bone were non-penetrating and allowed movements, while the surfaces between the screws and bone were bonded to assume they were rigidly fixed to bone. (Figure 2) The condylar region of the model was fully restrained. The mid-symphysis was restrained with a slider/roller restraint which allows movement in the vertical plane only and simulates the presence of the other half of the mandible (Figure 2).

Forces were applied in the angle region of the mandible to simulate the masseter muscle action. To simulate bite forces, either the molar or incisal occlusal surfaces were restrained at one time. Forces of 50, 75 and $100 \mathrm{~N}$ were applied for the incisor bite simulation, and 100, 200 and $300 \mathrm{~N}$ for molar bite simulation.

FEA was run in all models at the various bite forces and mandibular movements. Maximum von Mises stress in the fixation, and maximum displacement of the whole model were recorded. Von Mises stress is the equivalent tensile stress used to predict the yielding of materials, when they are placed under loads from different directions.

\section{Results}

\subsection{Stress in Fixation Techniques}

The maximum von Mises stress in all models are shown in Table 3 . The $1.7 \mathrm{~mm}$ miniplate recorded the highest von Mises stress, when compared to the bi-cortical screws and $2.0 \mathrm{~mm}$ miniplate, at all forces and mandibular movements. The maximum stress recorded in all fixation techniques were within the material yield before permanent deformity. Stress distributions in each fixation technique and models, at maximum force application, are shown in Figures 3-5. The stresses in the $1.7 \mathrm{~mm}$ and $2.0 \mathrm{~mm}$ miniplate are mainly concentrated in the 


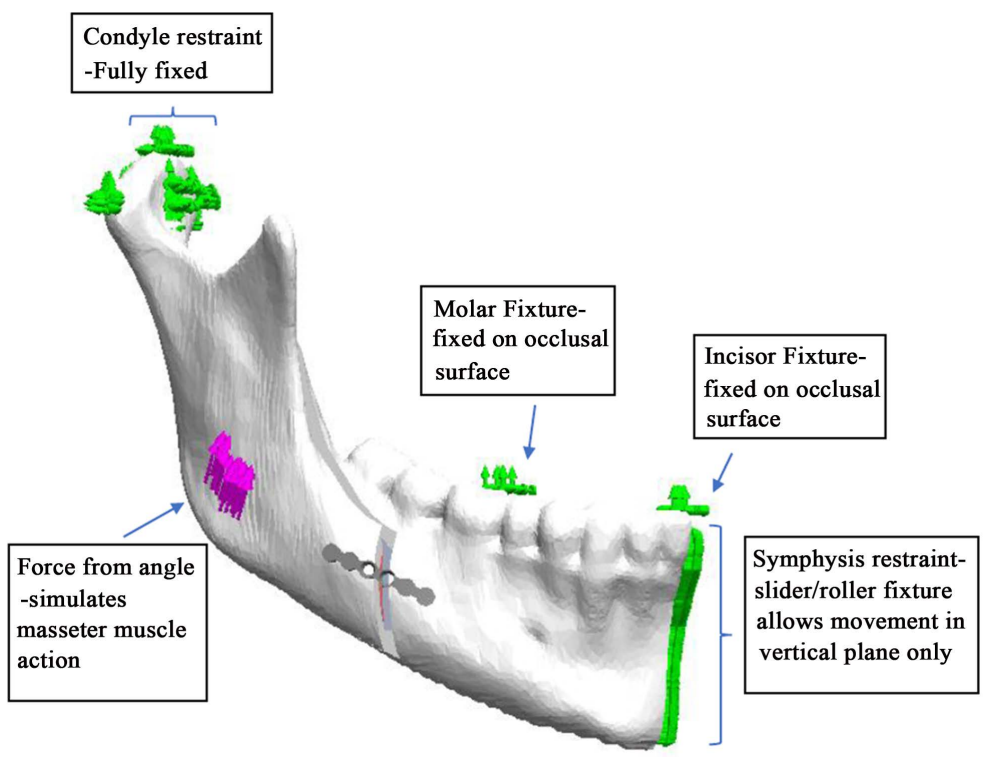

Figure 2. Restraints, boundaries and force application in the FEA simulation model.

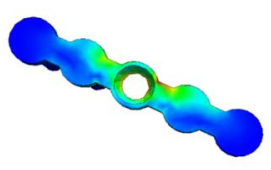

(a)

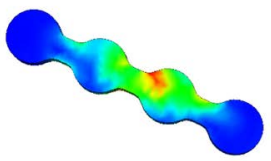

(b)

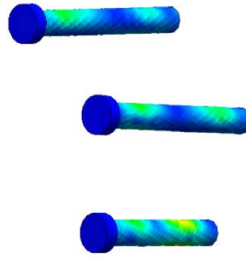

(c)

Figure 3. Stress distribution in fixation techniques at $3 \mathrm{~mm}$ mandibular setback and 300 $\mathrm{N}$ force. (a) Model 1: 5-hole $1.7 \mathrm{~mm}$ miniplate; (b) Model 2: $2.0 \mathrm{~mm}$ miniplate no gap; (c) Model 3: $2.0 \mathrm{~mm}$ bi-cortical screws.

Table 3. Maximum von Mises stress ( $\mathrm{MPa}$ ) in fixation techniques for all simulation models.

\begin{tabular}{|c|c|c|c|c|c|c|c|c|}
\hline $\begin{array}{l}\text { Mandibular } \\
\text { movement }\end{array}$ & Model & Force & $50 \mathrm{~N}$ & $75 \mathrm{~N}$ & $100 \mathrm{~N}$ & $100 \mathrm{~N}$ & $200 \mathrm{~N}$ & $300 \mathrm{~N}$ \\
\hline \multirow[t]{3}{*}{$3 \mathrm{~mm}$ setback } & 1 (1.7 mm miniplate) & & 107.9 & 162.0 & 216.3 & 229.8 & 406.3 & 456.3 \\
\hline & $2(2.0 \mathrm{~mm}$ miniplate $)$ & & 30.7 & 46.1 & 61.5 & 75.8 & 152.2 & 229.2 \\
\hline & $\begin{array}{c}3(2.0 \mathrm{~mm} \\
\text { bi-cortical screws })\end{array}$ & & 38.2 & 57.3 & 75.9 & 67.8 & 111.4 & 145.2 \\
\hline \multirow[t]{3}{*}{$\begin{array}{c}3 \mathrm{~mm} \\
\text { advancement }\end{array}$} & 4 (1.7 mm miniplate) & & 133.5 & 200.6 & 267.8 & 266.3 & 537 & 812 \\
\hline & 5 (2.0 mm miniplate $)$ & & 50.5 & 75.8 & 101.3 & 110.1 & 221.5 & 334.3 \\
\hline & $\begin{array}{c}6(2.0 \mathrm{~mm} \\
\text { bi-cortical screws })\end{array}$ & & 26.5 & 39.7 & 52.9 & 48.7 & 97.3 & 146 \\
\hline \multirow[t]{3}{*}{$\begin{array}{l}7 \mathrm{~mm} \\
\text { advancement }\end{array}$} & 7 (1.7 mm miniplate) & & 148.7 & 223.5 & 298.8 & 307.5 & 621.3 & 929.7 \\
\hline & 8 (2.0 mm miniplate $)$ & & 75.3 & 131.1 & 151.1 & 151.2 & 304.1 & 458.1 \\
\hline & $\begin{array}{c}9(2.0 \mathrm{~mm} \\
\text { bi-cortical screws })\end{array}$ & & 30.4 & 45.5 & 60.7 & 56.3 & 112.4 & 168.5 \\
\hline
\end{tabular}




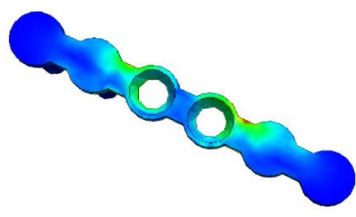

(a)

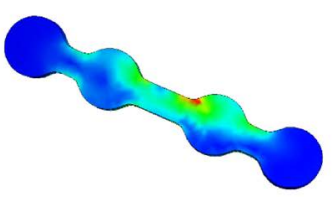

(b)

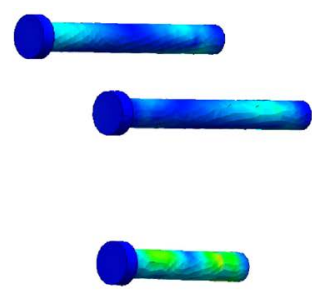

(c)

Figure 4. Stress distribution in fixation techniques at $3 \mathrm{~mm}$ mandibular advancement and $300 \mathrm{~N}$ force. (a) Model 4: 6-hole $1.7 \mathrm{~mm}$ miniplate; (b) Model 5: $2.0 \mathrm{~mm}$ miniplate with $4.4 \mathrm{~mm}$ gap; (c) Model 6: $2.0 \mathrm{~mm}$ bi-cortical screws.

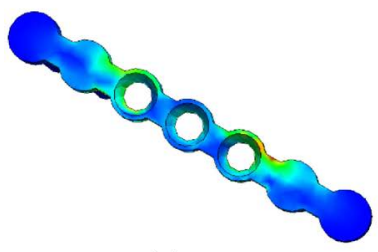

(a)

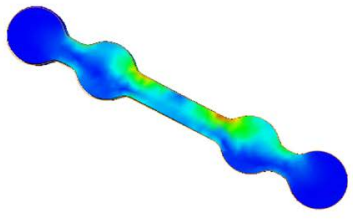

(b)

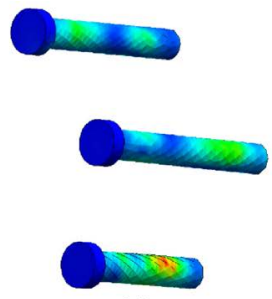

(c)

Figure 5. Stress distribution in fixation techniques at $7 \mathrm{~mm}$ mandibular setback and 300 $\mathrm{N}$ force. (a) Model 7: 7-hole $1.7 \mathrm{~mm}$ miniplate; (b) Model 8: $2.0 \mathrm{~mm}$ miniplate with $8 \mathrm{~mm}$ gap; (c) Model 9: $2.0 \mathrm{~mm}$ bi-cortical screws.

superior-distal region of the connector region. The stresses in the $2.0 \mathrm{~mm}$ bi-cortical screws are dissipated among all screws, but more concentrated in the inferior-distal screw, and maximum stress is seen at the lingual cortical-cancellous junction.

A Wilcoxon rank sum test was carried out for the non-normal distributed data. The test showed statistically significant difference between the $1.7 \mathrm{~mm} \mathrm{mi}$ niplate and the $2.0 \mathrm{~mm}$ miniplate, with $\mathrm{P}<0.05(\mathrm{~W}=263$, $\mathrm{p}$-value $=$ 0.0009862 ). There was also significant difference between the $1.7 \mathrm{~mm}$ and 2.0 $\mathrm{mm}$ Bi-cortical screws, $\mathrm{P}<0.05(\mathrm{~W}=314$, $\mathrm{p}$-value $=3.063 \mathrm{e}-08)$, and between the $2.0 \mathrm{~mm}$ miniplate and $2.0 \mathrm{~mm}$ Bi-cortical screws, $\mathrm{P}<0.05(\mathrm{~W}=238$, $\mathrm{p}$-value $=0.01557)$.

\subsection{Mandible Segment Displacement}

Maximum displacement was seen in the proximal segment of the mandible model in all cases. This is consistent with the location of force application, which is in the angle region. The maximum displacement for all models is shown in Table 4. The highest displacement is seen in model 7, which consists of $1.7 \mathrm{~mm}$ miniplate fixation with a $7 \mathrm{~mm}$ mandibular advancement. While the least displacement is seen in model 3 with $2.0 \mathrm{~mm}$ bi-cortical screws at $3 \mathrm{~mm}$ mandibular setback.

Statistical significant difference was seen between the $1.7 \mathrm{~mm}$ miniplate and the $2.0 \mathrm{~mm}$ miniplate models, with $\mathrm{P}<0.05(\mathrm{~W}=235$, $\mathrm{p}$-value $=0.02046)$, between the $1.7 \mathrm{~mm}$ and $2.0 \mathrm{~mm}$ bi-cortical screws models, $\mathrm{P}<0.05(\mathrm{~W}=282$, 
Table 4. Maximum displacement $(\mathrm{mm})$ in proximal mandible segment for all simulation models.

\begin{tabular}{|c|c|c|c|c|c|c|c|c|}
\hline $\begin{array}{l}\text { Mandibular } \\
\text { movement }\end{array}$ & Model & Force: & $50 \mathrm{~N}$ & $75 \mathrm{~N}$ & $100 \mathrm{~N}$ & $100 \mathrm{~N}$ & $200 \mathrm{~N}$ & $300 \mathrm{~N}$ \\
\hline \multirow[t]{3}{*}{$3 \mathrm{~mm}$ setback } & 1 (1.7 mm miniplate) & & 0.068 & 0.102 & 0.137 & 0.132 & 0.252 & 0.332 \\
\hline & $2(2.0 \mathrm{~mm}$ miniplate $)$ & & 0.049 & 0.073 & 0.098 & 0.092 & 0.185 & 0.281 \\
\hline & $\begin{array}{c}3(2.0 \mathrm{~mm} \\
\text { bi-cortical screws })\end{array}$ & & 0.033 & 0.052 & 0.069 & 0.062 & 0.118 & 0.169 \\
\hline \multirow[t]{3}{*}{$\begin{array}{c}3 \mathrm{~mm} \\
\text { advancement }\end{array}$} & 4 (1.7 mm miniplate) & & 0.114 & 0.172 & 0.230 & 0.223 & 0.449 & 0.680 \\
\hline & 5 (2.0 mm miniplate) & & 0.053 & 0.079 & 0.107 & 0.102 & 0.207 & 0.315 \\
\hline & $\begin{array}{c}6(2.0 \mathrm{~mm} \\
\text { bi-cortical screws })\end{array}$ & & 0.039 & 0.059 & 0.079 & 0.071 & 0.142 & 0.214 \\
\hline \multirow[t]{3}{*}{$\begin{array}{c}7 \mathrm{~mm} \\
\text { advancement }\end{array}$} & 7 (1.7 mm miniplate) & & 0.146 & 0.219 & 0.294 & 0.289 & 0.581 & 0.879 \\
\hline & $8(2.0 \mathrm{~mm}$ miniplate $)$ & & 0.081 & 0.122 & 0.164 & 0.150 & 0.303 & 0.459 \\
\hline & $\begin{array}{c}9(2.0 \mathrm{~mm} \\
\text { bi-cortical screws })\end{array}$ & & 0.042 & 0.064 & 0.086 & 0.077 & 0.155 & 0.233 \\
\hline
\end{tabular}

p-value $=5.811 \mathrm{e}-05)$, and between the $2.0 \mathrm{~mm}$ miniplate and $2.0 \mathrm{~mm}$ bi-cortical screws models, $\mathrm{P}<0.05(\mathrm{~W}=231, \mathrm{p}$-value $=0.02896)$.

\subsection{Effect of Mandibular Movements on Maximum Stress and Displacement}

In larger advancements, the fixation techniques absorb more stress when compared to setback movement. The effect of mandibular movements on stresses in fixations can be illustrated in Figure 6 .

Displacement of the proximal segment increases as the mandible is advanced further (Figure 7). Displacements for models in the mandibular setback movement are much less compared to advancement movements.

\section{Discussion}

The use of miniplates smaller than $2.0 \mathrm{~mm}$ in mandibular fixation is uncommon, but has recently gained interest by clinicians and researchers. In 2010, Burm et al. studied the use of $1.2 \mathrm{~mm}$ microplate and mono-cortical screws in the management of mandibular fractures and found considerable success compared to other conventional $2.0 \mathrm{~mm}$ miniplates [19]. He explained the advantages of smaller microplates, which include less foreign body reaction, less palpability, and improved patient acceptability. Ahmed et al. in 2017 who compared $2.0 \mathrm{~mm}$ miniplates with $1.5 \mathrm{~mm}$ miniplates in the management of mandibular symphysis fractures using FEA [20]. They found that there was no significant difference in the stresses developed in either of the bone plating system. Yeo et al. in 2017 compared the effects between $1.7 \mathrm{~mm}$ upper border sliding plates and positional screws in neurosensory disturbances following BSSO advancement. 


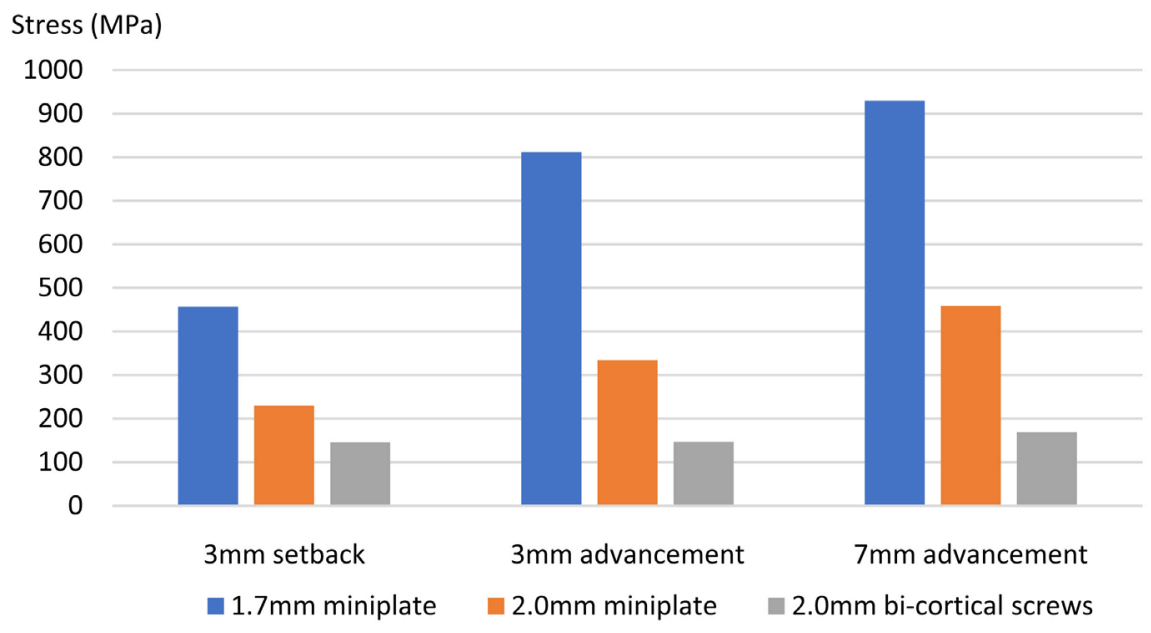

Figure 6. Maximum stress in fixation techniques in all mandibular movements.

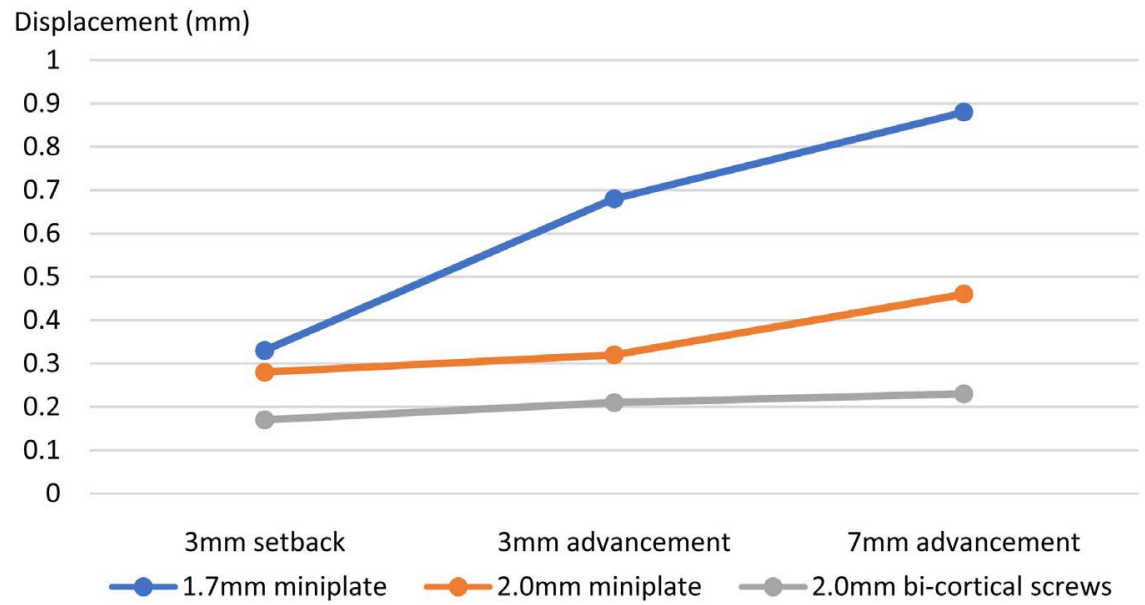

Figure 7. Maximum displacement in simulation models for all mandibular movements.

He showed that there was insufficient evidence to prove one was better than the other [5].

The present study has shown the comparison of biomechanical properties in 3 fixation techniques when various forces and different mandibular movements are applied. The results of this study support the findings of previous FEA studies by showing that the $2.0 \mathrm{~mm}$ bi-cortical screws are more rigid than miniplate fixations [6] [7] [21]. These studies however, have not made biomechanical comparisons of fixation techniques at various mandible movements.

The $2.0 \mathrm{~mm}$ bi-cortical screws recorded the least stress and displacements compared to the $2.0 \mathrm{~mm}$ miniplate and $1.7 \mathrm{~mm}$ miniplate for all mandibular movements and forces. The bi-cortical screws are more rigid than the miniplates with monocortical screws, probably because they penetrate both buccal and lingual cortices of the mandible segments [22]. This study does not show any deformation in the miniplates, and areas of high stresses represent as red color can be either tensional or compressional stresses (Figures 3-5). Minimizing manipulation of the miniplates in these high stress regions is highly advised to avoid 
complications such as plate fracture.

The amount of displacement is an indication of fixation rigidity, and the bi-cortical screws were shown to be the most rigid fixation. Miniplates can be rigid or functionally stable and clinically have both been proven to be successful in the treatment of mandibular fractures [23]. In our study, the maximum displacement is less than $0.9 \mathrm{~mm}$ which was seen in Model 7 that consisted of the $1.7 \mathrm{~mm}$ miniplate at $7 \mathrm{~mm}$ mandibular advancement. The amount of displacement is small in the simulation models and is probably not clinically significant. Claes in 1998 claims that some degree of micromotion in bone in-fact enhances callus formation during bone healing, and this may be an advantage of semi-rigid fixation [24]. Least displacement is seen in the setback models, and is likely due to the close approximation of the mandible segments. Like mandibular fractures, the close approximation of bony segments increases stability of the fracture [22].

In FEA, the setup of simulation models is important, as any changes in force locations or restraints can affect the results. Comparing results with other FEA orthognathic studies is difficult due to difference in model construction, mesh element numbers, and various simulation protocols. There are studies that use a full mandible [25] while others opted for the hemi-mandible [6] [7] [21]. The reason highly depend on the computer resources and in certain instances, the models require simplification to reduce computational demand.

This study simulated a hemi-mandible with a cortical and cancellous bone layer. The condyle was fully restrained, while the symphysis region had a slider/roller restraint which permits movement in the vertical plane only and simulates, in our simplified model, the other mandible half. The occlusal surface of the molar and incisor were fixed according to the type of load applied. Forces of 50,75 and $100 \mathrm{~N}$ were applied with the incisor fixed to simulate incisal biting while 100, 200 and $300 \mathrm{~N}$ applied for molar bite force. Bite forces were obtained from studies investigating post-operative bite forces in orthognathic surgery patients [16] [17] [18]. During the post-operative period, bite forces in healthy adults can drop to $50 \%$ or more, and gradually increases to normal after 3 months to 2 years. This study did not include maximum normal bite forces as the fixation techniques are most crucial during the bone healing period of 3 to 6 months.

Mandibular sagittal split osteotomy is a recognized orthognathic technique and it allows various movement such as advancement, setback, and rotation. The type of mandibular movement required is the result of surgical and orthodontic planning and reflects the patient's dentofacial deformity. The fixation technique applied must be strong enough to provide sufficient stability, while minimizing risks and complications. Bi-cortical screws are rigid but known to have increased risks to the inferior alveolar and lingual nerve [26]. Miniplates are less rigid, have higher removal rates, and can cause irritation to the mucosa and gingiva, even when placed appropriately [27]. Both bi-cortical screws and miniplate fixation have been shown to provide similar skeletal stability in the long term [28] 
[29]. The successful outcome of orthognathic surgery does not only rely on the fixation techniques but other factors, including severity of the dentofacial deformity, surgical planning, surgeon's technique, and patient's soft and hard tissues.

Limitations exist with any computational experiments. This study only involves the use of a single Caucasian female mandible CT scan. Although replicable and capable of being manipulated in the software, it does not represent a full population of different sized mandibles. Condylar torque was not considered following fixation placement. Condylar torque is a known phenomenon following fixation of a mandibular osteotomy. As the models did not include the temporomandibular joint soft tissue structures and the condyle was fixed during simulation, condylar torque was not assessed. Although these limitations were present, they were mitigated by being present in all models, which were compared with one another.

\section{Conclusion}

This study looked at the biomechanical properties of using a smaller $1.7 \mathrm{~mm}$ miniplate in mandibular orthognathic surgery with various movements. Although it recorded the highest stress among the other techniques, the stress was within the material yield of $950 \mathrm{MPa}$ for all mandibular movements. In conclusion, the $1.7 \mathrm{~mm}$ miniplate has adequate strength when applied and can be used in mandibular osteotomy, although statistically less rigid when compared to the conventional $2.0 \mathrm{~mm}$ miniplate and $2.0 \mathrm{~mm}$ bi-cortical screws, especially for larger movements.

\section{Conflicts of Interest}

The authors declare no conflicts of interest regarding the publication of this paper.

\section{References}

[1] Obwegeser, H. (1964) The Indications for Surgical Correction of Mandibular Deformity by the Sagittal Splitting Technique. British Journal of Oral Surgery, 1, 157-171. https://doi.org/10.1016/S0007-117X(63)80067-0

[2] Steinhauser, E.W. (1996) Historical Development of Orthognathic Surgery. Journal of Cranio-Maxillo-Facial Surgery, 24, 195-204. https://doi.org/10.1016/S1010-5182(96)80002-3

[3] Schatzker, J. (1995) Changes in the AO/ASIF Principles and Methods. Injury, 26, B51-B56. https://doi.org/10.1016/0020-1383(95)96899-F

[4] Peterson, G.P., Haug, R.H. and Van Sickels, J. (2005) A Biomechanical Evaluation of Bilateral Sagittal Ramus Osteotomy F Ixation Techniques. Journal of Oral and Maxillofacial Surgery, 63, 1317-1324. https://doi.org/10.1016/j.joms.2005.05.301

[5] Yeo, X.H., et al. (2017) Neurosensory Deficit Following Mandibular Sagittal Split Osteotomy: A Comparative Study between Positional Screws and Miniplates Fixation. Surgeon, 15, 278-281. https://doi.org/10.1016/j.surge.2016.07.001 
[6] Erkmen, E., et al. (2005) Comparison of Different Fixation Methods Following Sagittal Split Ramus Osteotomies Using Three-Dimensional Finite Elements Analysis. Part 1: Advancement Surgery-Posterior Loading. International Journal of Oral and Maxillofacial Surgery, 34, 551-558. https://doi.org/10.1016/j.ijom.2004.10.009

[7] Erkmen, E., et al. (2005) Three-Dimensional Finite Element Analysis Used to Compare Methods of Fixation after Sagittal Split Ramus Osteotomy: Setback Surgery-Posterior Loading. British Journal of Oral and Maxillofacial Surgery, 43, 97-104. https://doi.org/10.1016/j.bjoms.2004.10.007

[8] Oguz, Y., et al. (2015) In Vitro Biomechanical Comparison of Six Different Fixation Methods Following 5-mm Sagittal Split Advancement Osteotomies. International Journal of Oral and Maxillofacial Surgery, 44, 984-988. https://doi.org/10.1016/j.ijom.2014.11.019

[9] Oguz, Y., et al. (2009) Stability of Locking and Conventional 2.0-mm Miniplate/Screw Systems after Sagittal Split Ramus Osteotomy: Finite Element Analysis. Oral Surgery, Oral Medicine, Oral Pathology, Oral Radiology, and Endodontology, 108, 174-177. https://doi.org/10.1016/j.tripleo.2009.03.051

[10] Freedman, M., Ring, M. and Stassen, L.F. (2015) Effect of Alveolar Bone Support on Zygomatic Implants in an Extra-Sinus Position-A Finite Element Analysis Study. International Journal of Oral and Maxillofacial Surgery, 44, 785-790. https://doi.org/10.1016/j.ijom.2015.01.009

[11] Arbag, H., et al. (2008) Comparative Evaluation of Different Miniplates for Internal Fixation of Mandible Fractures Using Finite Element Analysis. Journal of Oral and Maxillofacial Surgery, 66, 1225-1232. https://doi.org/10.1016/j.joms.2005.11.092

[12] Centro de Tecnologia da Informação Renato Archer (CTI) (2001) InVesalius.

[13] Netfabb GmbH, Parsberg, Germany (2016) Netfabb. http://www.netfabb.com/

[14] Rhinoceros. http://www.rhino3d.com/

[15] Dassault Systèmes Solid Works Corporation (2016) SolidWorks.

[16] Harada, K., et al. (2000) Measure of Bite Force and Occlusal Contact Area before and after Bilateral Sagittal Split Ramus Osteotomy of the Mandible Using a New Pressure-Sensitive Device: A Preliminary Report. Journal of Oral and Maxillofacial Surgery, 58, 370-373. https://doi.org/10.1016/S0278-2391(00)90913-3

[17] Ellis, E., Throckmorton, G.S. and Sinn, D.P. (1996) Bite Forces before and after Surgical Correction of Mandibular Prognathism. Journal of Oral and Maxillofacial Surgery, 54, 176-181. https://doi.org/10.1016/S0278-2391(96)90443-7

[18] Throckmorton, G.S., Buschang, P.H. and Ellis, E. (1996) Improvement of Maximum Occlusal Forces after Orthognathic Surgery. Journal of Oral and Maxillofacial Surgery, 54, 1080-1086. https://doi.org/10.1016/S0278-2391(96)90165-2

[19] Burm, J.S. and Hansen, J.E. (2010) The Use of Microplates for Internal Fixation of Mandibular Fractures. Plastic and Reconstructive Surgery, 125, 1485-1492. https://doi.org/10.1097/PRS.0b013e3181d51244

[20] Ahmed, S.S., et al. (2017) Role of $1.5 \mathrm{~mm}$ Microplates in Treatment of Symphyseal Fracture of Mandible: A Stress Analysis Based Comparative Study. Journal of Oral Biology and Craniofacial Research, 7, 119-122. https://doi.org/10.1016/j.jobcr.2017.03.009

[21] Albougha, S., et al. (2015) Assessment of Sagittal Split Ramus Osteotomy Rigid Internal Fixation Techniques Using a Finite Element Method. International Journal of Oral and Maxillofacial Surgery, 44, 823-829.

https://doi.org/10.1016/j.ijom.2015.02.006 
[22] Ellis, E. (1993) Rigid Skeletal Fixation of Fractures. Journal of Oral and Maxillofacial Surgery, 51, 163-173. https://doi.org/10.1016/S0278-2391(10)80016-3

[23] Ellis, E. (2004) Maxillofacial Trauma: Rigid versus Nonrigid Fixation. In: Miloro, M., Ed., Peterson's Principles of Oral and Maxillofacial Surgery, BC Decker Inc., Hamilton, 371-382.

[24] Claes, L.E., et al. (1998) Effects of Mechanical Factors on the Fracture Healing Process. Clinical Orthopaedics and Related Research, 355, S132-S147. https://doi.org/10.1097/00003086-199810001-00015

[25] Stringhini, D.J., et al. (2016) Resistance and Stress Finite Element Analysis of Different Types of Fixation for Mandibular Orthognathic Surgery. Brazilian Dental Journal, 27, 284-291. https://doi.org/10.1590/0103-6440201600336

[26] Bouwman, J.P., et al. (1995) Screw Fixation Following Bilateral Sagittal Ramus Osteotomy for Mandibular Advancement-Complications in 700 Consecutive Cases. British Journal of Oral and Maxillofacial Surgery, 33, 231-234. https://doi.org/10.1016/0266-4356(95)90006-3

[27] Ochs, M.W. (2003) Bicortical Screw Stabilization of Sagittal Split Osteotomies. Journal of Oral and Maxillofacial Surgery, 61, 1477-1484.

https://doi.org/10.1016/j.joms.2003.07.003

[28] Joss, C.U. and Vassalli, I.M. (2009) Stability after Bilateral Sagittal Split Osteotomy Advancement Surgery with Rigid Internal Fixation: A Systematic Review. Journal of Oral and Maxillofacial Surgery, 67, 301-313.

https://doi.org/10.1016/j.joms.2008.06.060

[29] Al-Moraissi, E.A. and Ellis, E. (2016) Stability of Bicortical Screw versus Plate Fixation after Mandibular Setback with the Bilateral Sagittal Split Osteotomy: A Systematic Review and Meta-Analysis. International Journal of Oral and Maxillofacial Surgery, 45, 1-7. https://doi.org/10.1016/j.ijom.2015.09.017 


\section{Terms and Abbreviations}

\begin{tabular}{|c|c|}
\hline Term & Definition \\
\hline Anisotropic & $\begin{array}{l}\text { A material that consists of more than one property } \\
\text { in various areas and direction }\end{array}$ \\
\hline Bi-cortical screws & Screws that penetrate both cortices of bone \\
\hline Biomechanical & $\begin{array}{l}\text { Study of the action of external and internal forces on the living body, } \\
\text { especially on the skeletal system }\end{array}$ \\
\hline CT & $\begin{array}{l}\text { Computer tomography-computer-processed combinations of } \\
\text { many X-ray measurements taken from different angles to produce } \\
\text { cross-sectional images of specific areas of a scanned object }\end{array}$ \\
\hline DICOM & $\begin{array}{l}\text { Digital imaging and communications in medicine. } \\
\text { It is an image format usually containing CT images }\end{array}$ \\
\hline Discretization (Meshing) & The process of changing a solid body into smaller finite elements \\
\hline $\begin{array}{l}\text { Elastic Modulus } \\
\text { (Young's Modulus) }\end{array}$ & Measurement of stiffness of a solid material \\
\hline FEA & $\begin{array}{l}\text { Finite Element Analysis, a computerized method for predicting } \\
\text { how a product reacts to real-world forces, vibration, heat, } \\
\text { fluid flow, and other physical effects }\end{array}$ \\
\hline Hooke’s Law & $\begin{array}{l}\text { The principle of stress imposed on a solid is directly proportional } \\
\text { to the strain produced, within the elastic limit }\end{array}$ \\
\hline IGES & $\begin{array}{l}\text { Initial Graphics Exchange Specification, file format that allows } \\
\text { the digital exchange of information among computer-aided } \\
\text { design (CAD) systems }\end{array}$ \\
\hline Invesalius & Computer software that allows conversion of DICOM images into STL \\
\hline In-vitro & Studies performed outside of biological context \\
\hline Isotropic & A material that is uniform in all areas and direction \\
\hline Mono-cortical screws & Screws that penetrate a single bone cortex \\
\hline Netfabb & Computer software that allows editing and repair of surface polygons \\
\hline Newton $(\mathrm{N})$ & A measurement unit for force \\
\hline NURBS & $\begin{array}{l}\text { Non-uniform rational basis spline (NURBS) is a mathematical } \\
\text { model commonly used in computer graphics for generating } \\
\text { and representing curves and surfaces }\end{array}$ \\
\hline $\mathrm{Pa}$ (Pascal) & $\begin{array}{l}\text { Pascal, SI unit to quantify stress which is equivalent to } 1 \mathrm{~N} \text { per } \\
\text { square meter. } 1 \mathrm{Mega} \text { Pascal }(\mathrm{MPa})=1000 \mathrm{~Pa} \text {, and } \\
1 \text { Giga Pascal }(\mathrm{GPa})=1000 \mathrm{MPa}\end{array}$ \\
\hline Poisson's ratio & $\begin{array}{l}\text { The ability of a structure to resist deformation in a direction } \\
\text { perpendicular to that of the applied load. }\end{array}$ \\
\hline Rhinoceros & Computer software that allows creation and manipulation of NURBS \\
\hline Simulation in Solidworks & An internal programme of Solidworks that runs FEA \\
\hline Solidworks & $\begin{array}{l}\text { Computer software that allows creation, editing } \\
\text { and manipulation of 3D solid models }\end{array}$ \\
\hline STL & $\begin{array}{l}\text { Stereolithography, a file format used to represent surfaces } \\
\text { with a series of triangles }\end{array}$ \\
\hline Strain & The measurement of the deformation of a material \\
\hline Stress & The force per unit area applied to an object \\
\hline Von Mises Stress & $\begin{array}{l}\text { The equivalent tensile stress used to predict the yielding of materials, } \\
\text { when they are placed under loads from different directions }\end{array}$ \\
\hline
\end{tabular}

